\title{
Surgical Results of Left Ventricular Lead Implantation for Cardiac Resynchronization Therapy*
}

\author{
Ozcan Gur ${ }^{1 \#}$, Selami Gurkan ${ }^{1}$, Demet Ozkaramanli Gur², Habib Cakir³, \\ Cayan Akkoyun ${ }^{1}$, Turan Ege ${ }^{1}$ \\ ${ }^{1}$ Cardiovascular Surgery Department, Medical Faculty, Namik Kemal University, Yil Tekirdag, Turkey \\ ${ }^{2}$ Cardiology Department, Tekirdag State Hospital, Yil Tekirdag, Turkey \\ ${ }^{3}$ Cardiovascular Surgery Department, Adana Numune Hospital, Yil Tekirdag, Turkey \\ Email: \#ozcangur@hotmail.com
}

Received April 16, 2013; revised May 17, 2013; accepted May 25, 2013

Copyright (C) 2013 Ozcan Gur et al. This is an open access article distributed under the Creative Commons Attribution License, which permits unrestricted use, distribution, and reproduction in any medium, provided the original work is properly cited.

\begin{abstract}
Objectives: Cardiac resynchronisation therapy (CRT) has proven its effectiveness in patients with symptomatic heart failure [1,2]. Although rewarding, the procedure of biventricular pacemaker implantation is challenging and subsequently fails in $8 \%-11 \%$ of patients. In patients whose left ventricular (LV) electrode cannot be placed transvenously, surgical implantation of an epicardial electrode can be achieved. Methods: Seventeen patients (14 male, 3 female), among whom LV electrode was failed to be placed transvenously, were included into our study. The epicardial LV electrodes were implanted through anterior mini thoracotomy. The patients were followed up for approximate six months and complications, ejection fraction (EF), New York Heart Association (NYHA) class, QRS durations as well as pacing parameters were recorded. Results: Mean age of the patients was $64.4 \pm 7.01$ (54 - 79) years. Preoperative mean EF of the patients was $26.1 \% \pm 3.7 \%$. The LV electrode was placed at the optimal place on the lateral LV wall through left sided mini thoracotomy. The mean duration of the operation was $26.76 \pm 8.12$ minutes and the mean hospital stay was $2.05 \pm 0.42$ days. There were no intraoperative or postoperative complications. Only 1 patient had LV electrode displaced on the 3rd postoperative month and the patient was reoperated successfully. The EF on the 6th postoperative month was $29.4 \% \pm 3.81 \%$ and NYHA class was $2.58 \pm 0.5$. The etiology of heart failure had no influence on outcome. Conclusions: Surgical implantation of LV lead is associated with low complication rates and excellent follow-up results without exposure to radiation. Thus epicardial leads can be proposed as equal alternative to transvenous leads.
\end{abstract}

Keywords: Cardiac Resynchronization Therapy; Surgical Epicardial Lead Implantation

\section{Introduction}

Among approximate $30 \%$ of patients with left ventricular (LV) dysfunction, the QRS duration is longer than 120 milliseconds demonstrating ventricular dyssynchrony [1]. The cardiac resynchronization therapy (CRT) thus targets the delayed conduction sites and activates left ventricle through lateral branches of the coronary sinus. This increases myocardial performance by synchronous contraction of both ventricles as well as harmonizing atrioventricular sequence. However, among $8 \%-11 \%$ of patients, the procedure fails due to difficulties in placing LV electrode [2,3]. Surgical implantation of the electrode is mandatory in such cases [4]. Here, we aime to present the clinical results of 17 patients who were operated on

\footnotetext{
*Conflict of Interest: No conflict of interest.

${ }^{\#}$ Corresponding author.
}

the implantation of LV electrodes.

\section{Patients and Methods}

Between 2009 and 2012, 17 patients (3 female, 14 male) with symptomatic heart failure and indications for CRT implantation Ejection fraction (EF) < 35\% and QRS > $120 \mathrm{sec}$ and symptomatic despite optimal medical therapy in whom transvenous LV lead implantation had failed were included into the study. The LV electrodes were implanted surgically through anterior mini thoracotomy.

The demographic data of the patients are shown in Table 1. Mean age of the patients was $64.4 \pm 7.01$ (54 79) years, and the mean $\mathrm{EF}$ was $26.1 \% \pm 3.7 \%$ with poor functional capacity (NYHA class > 3). The mean QRS duration was $161.76 \pm 9.67$ milliseconds. 
Table 1. Preoperative demographic data of the patients (n: 17).

\begin{tabular}{lc}
\hline Age (years ) & $64.35 \pm 7.0$ \\
\hline Sex (male \%) & $14(82.35)$ \\
Ejection Fraction (\%) & $26.05 \pm 3.69$ \\
NYHA $^{*}(\%)$ & $3.4 \pm 0.51$ \\
Diabetes mellitus (\%) & $13(76.4)$ \\
COLD ${ }^{*}(\%)$ & $8(47.05)$ \\
QRS duration(milliseconds) & $161.76 \pm 9.67$ \\
Nonischemic CMP* (\%) & $8(47.05)$ \\
Ischemic CMP (\%) & $9(52.94)$ \\
\hline
\end{tabular}

NYHA: New York Heart Association functional class, COLD: Chronic Obstructive Lung Disease, CMP: Cardiomyopathy.

Half of the patients had ischemic heart disease as the etiology of heart failure while the other half had dilated cardiomyopathy.

The reasons for failure of transvenous LV lead implantation are presented in Table 2. In most of the patients $(n=12)$ the procedure failed due to failure to cannulate coronary sinus. Two patients were operated because of acute LV lead dislodgement and 1 patient had coronary sinus dissection and rupture during the transvenous procedure. One patient had dextrocardia and one patient had bilateral upper extremit deep venous thrombosis and had all electrodes implanted surgically includeing right ventricular and right atrial electrodes.

\section{Surgical Technique}

The patients were operated under general anesthesia, entubated with double lumen endotracheal tube, and ventilated unilaterally during the procedure. In 15 patients, LV was exposed through left sided mini thorachotomy while right sided thorachotomy was performed in one patient with dextrocardia, and bilateral thoracotomy for implantation of all electrodes was performed in one patient with bilateral upper extremity deep venous thrombosis (Figure 1).

The approporiate site of implantation on LV wall was selected via inspection and palpation to exclude scarred tissue. The pacing threshold and impedance measurements were done before deciding on the optimal sites. The leads (St. Jude Medical Inc., USA in 9 cases-Medtronic, Minneapolis, MN, USA in 8 cases) were then placed as proposed (Figure 2). The pockets for the generators were placed between the pectoral muscles below the clavicle in all but one patient and on the anterior abdominal wall in one patient in whom biventricular and right atrial electrodes were implanted surgically. The tips
Table 2. Etiology of unsuccessful transvenous lead implantation.

\begin{tabular}{lc}
\hline Failure to cannulate CS* & 12 \\
\hline Acute lead dislodgement & 2 \\
Dissection and rupture of CS & 1 \\
Bilateral upper extremity deep venous thrombosis & 1 \\
Dextrocardia & 1 \\
\hline${ }^{*}$ CS: Coronary sinus.
\end{tabular}

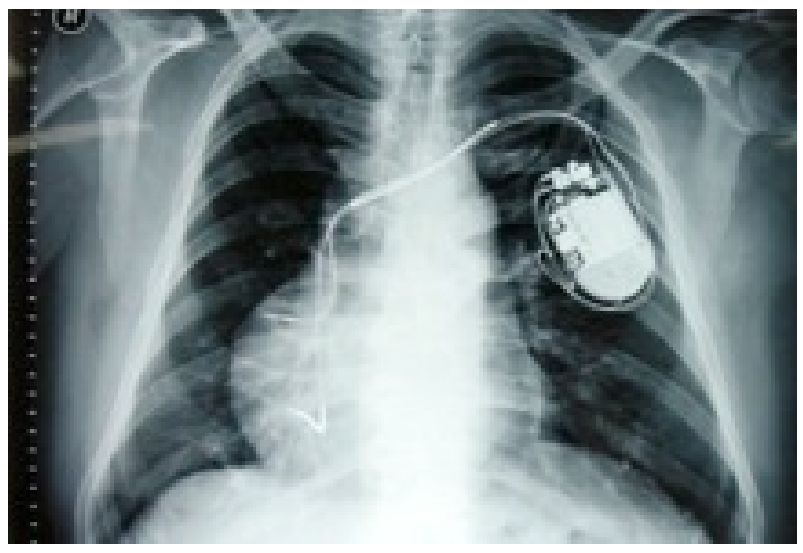

Figure 1. Bilateral thoracotomy for implantation was performed in one patient with bilateral upper extremity deep venous thrombosis.

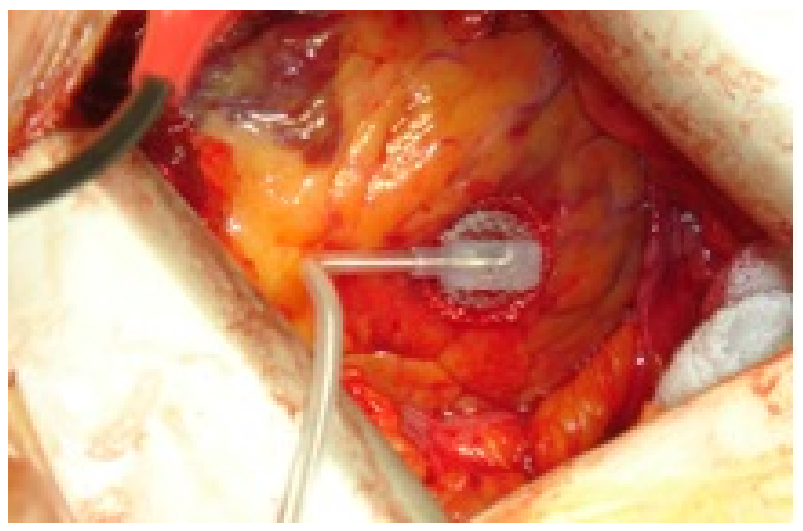

Figure 2. The approporiate site of implantation on LV wall was selected via inspection and palpation to exclude scarred tissue. The pacing threshold and impedance measurements were done before deciding on the optimal sites. The leads were then placed as proposed.

of the electrodes were connected to the appropriate sites at the generator through subcutaneous tunnels. The patients were then extubated and transferred to the intensive care unit with no perioperative complications.

The LV EF and CRT lead measurements were done at the 1 Week, 1 and 6 months postoperatively. The patients were followed for $6.3 \pm 1.13$ months postoperatively. 


\section{Statistical Analysis}

Results are expressed as mean values \pm SD or as numbers and percentages, as appropriate. Chi-square test was used for comparison of categorical data. All reported p-values were based on two-sided tests and a p-value of $<0.05$ was considered significant. All statistical calculations were performed using the SPSS version 19.0 software (SPSS Inc., Chicago, IL, USA).

\section{Results}

Preoperative data of the patients are shown in Table $\mathbf{1 .}$ Mean QRS duration was $161.76 \pm 9.67 \mathrm{msec}$, mean EF was $26.1 \pm 3.7$ and New York Heart Association (NYHA) functional class was $3.47 \pm 0.51$. Intraoperative lead parameters were obtained in all patients. The results are presented in Table 3. Mean epicardial pacing threshold was $0.97 \pm 0.32 \mathrm{~V}$ and the mean impedance was $378.23 \pm$ 104.17 ohms. The mean duration of the operation was $28.54 \pm 9.07$ minutes and the mean hospital stay was $2.05 \pm 042$ days.

The QRS duration on the 6th postoperative month was $148.76 \pm 7.52 \mathrm{msec}$, the EF was $29.4 \% \pm 3.81 \%$ and NYHA was $2.58 \pm 0.5$. There was no mortality observed during the follow up, and in only one patient had $\mathrm{LV}$ electrode displaced on the 3rd week after the operation. In another patient, the LV lead had a fracture at the bipolar junction site. Both patients were reoperated successfully. At the 6th Month of follow-up, the CRT device and leads were operating uneventfully in all patients. When the patients were divided into two groups in terms of ischemic and nonischemic etiology, there was no statistically significant influence of etiology on the procedural outcomes (Table 4).

\section{Discussion}

The CRT devices have shown to improve the symptoms,

Table 3. Immediate and follow-up results of surgical epicardial LV lead implantation.

\begin{tabular}{lc}
\hline Epicardial pacing threshold (V) & $0.97 \pm 0.32$ \\
\hline Impedance (ohms) & $378.23 \pm 104.17$ \\
Duration of the operation (minutes) & $28.54 \pm 9.07$ \\
ICU stay (days) & $2.05 \pm 042$ \\
Hospital stay (days) & \\
QRS duration (at 6 Months, msec) & $29.4 \pm 3.81$ \\
EF (at 6 Months, \%) & $2.58 \pm 0.5$ \\
NYHA (at 6 Months)
\end{tabular}

NYHA: New York Heart Association, EF: Ejection fraction ICU: Intensive Care Unit.
Table 4. Ethiological classification of heart failure.

\begin{tabular}{cccc}
\hline \multicolumn{3}{c}{ Ethiological Classification of Heart Failure } \\
\hline & $\begin{array}{c}\text { Ischemic CMP } \\
\text { (n: } 9 \text { ) }\end{array}$ & $\begin{array}{c}\text { Nonischemic CMP } \\
\text { (n: } 8)\end{array}$ & p Values \\
HS & $2.0 \pm 0.53$ & $2.11 \pm 0.33$ & NS \\
OpT & $26.12 \pm 7.07$ & $27.33 \pm 9.34$ & NS \\
Age & $64.12 \pm 8.09$ & $64.55 \pm 6.38$ & NS \\
Sex (male) & 7 & 7 & NS \\
EF1 & $25.62 \pm 3.88$ & $26.44 \pm 3.71$ & NS \\
EF2 & $29.25 \pm 3.32$ & $28.66 \pm 4.30$ & NS \\
NYHA 1 & $3.62 \pm 0.51$ & $3.33 \pm 0.50$ & NS \\
NYHA 2 & $2.75 \pm 0.46$ & $2.44 \pm 0.52$ & NS \\
\hline
\end{tabular}

HS: Hospital stay, OpT: Operation Time, $\mathbf{E F}^{1,2}$ : ${ }^{1}$ Preoperative, ${ }^{2}$ postoperative ejeksiyon fraksiyonu, NYHA ${ }^{1,2}$ : ${ }^{1}$ Preoperative, ${ }^{2}$ postoperative New York Heart Association Functional Class.

LVEF and quality of life in patients with heart failure and left bundle branch block via synchronous biventricular pacing $[2,4]$. In $66 \%$ - $75 \%$ of patients the symptoms improve with decreasing NYHA levels and the EF increase by $3 \%$ - 7\% [5].

The transvenous implantation of a CRT device is challenging due to varied venous anatomy of cardiac veins and is usually time consuming. The rate of unsuccessful $\mathrm{LV}$ lead implantation is reported to be $8 \%$ - $12 \%$ [6]. When transvenous lead implantation fails, surgical implantation of LV electrode is mandatory [7]. The reported duration of the transvenous procedure varies between 90 to 480 minutes; also increasing the fluoroscopic exposure to radiation of both the patient and the medical team [8]. Izutani et al. have reported the mean fluoroscopy time for biventricular pacing as $77 \pm 19 \mathrm{~min}$ [9]. Perisinakis et al. have analysed the radiation risks associated with fluoroscopically guided CRT procedures and reported that radiation exposure parameter (dose area productDAP) values of the patient as $4765 \mathrm{cGy} \cdot \mathrm{cm}^{2}$. They also have shown that this exceed threshold dose for the induction of skin effects [10]. An other study addressing the operator's side of the problem demonstrated that the radiation exposure of the hands is approximately $9.2 \mathrm{mSv}$, and the other part of the body as $1.2 \mathrm{mSv}$ [11].

Altough "surgical” implantation of the LV electrode is perceived as invasive, it takes shorter time and involves no radiation when compared to transvenous route [3]. In our study group, the mean duration of the procedure was $26.76 \pm 8.12$ minutes.

Among the surgical techniques used in epicardial lead implantation are mini thoracotomy, half sternotomy and thoracoscopic methods. Here we performed anterior thoracotomy of $5 \mathrm{~cm}$ in length; with no operative and posteoperative complications. 
The surgical implantation of LV electrode also has the advantage of correct lead positioning when compared to the transvenous route since it involves direct visualization and positioning of the lead at the obtuse marginal branch area. However, the rate of optimal positioning with transvenous route is $70 \%$ [12].

During the follow up, the lead impedance, $\mathrm{R}$ wave and threshold values were stable. There was only 1 patient with lead dislodgement on the 3rd Postoperative week who needed revision.

When the patients were divided in terms of ischemic or nonischemic etiology, and the effect of the etiology on the procedure and long-term outcomes were sought, there was no statistically significant influence detected. Yet, the small number of two groups (7 patients in each group) excludes a conclusion to be reached.

\section{Conclusion}

Surgical implantation of left ventricular lead is associated with low complication rates and excellent follow-up results without exposure to radiation. The etiology of cardiomyopathy (ischemic or nonischemic) has no influence on the success of the procedure. Thus, epicardial leads can be proposed as equal alternative to transvenous route.

\section{Study Limitations}

This study has some important limitations. First, this was a retrospective study and thus has all the limitations inherent to this type of study.

\section{REFERENCES}

[1] D. Furwell, N. R. Patel, A. Hall, et al., "How Many People with Heart Failure Are Appropriate for Biventricular Resynchronization?” European Heart Journal, Vol. 21, No. 15, 2000, pp. 1246-1250. doi:10.1053/euhj.1999.1985

[2] W. T. Abraham, W. G. Fisher, A. L. Smith, et al., "Cardiac Resynchronization in Chronic Heart Failure," The New England Journal of Medicine, Vol. 346, No. 24, 2002, pp. 1845-1853. doi:10.1056/NEJMoa013168

[3] F. A. McAlister, J. A. Ezekowitz, N. Wiebe, et al., "Systematic Review: Cardiac Resynchronization in Patients with Symptomatic Heart Failure,” Annals of Internal Medicine, Vol. 141, No. 5, 2004, pp. 381-390. doi:10.7326/0003-4819-141-5-200409070-00101

[4] A. E. Epstein, J. P. DiMarco, K. A. Ellenbogen, et al., "ACC/AHA/HRS 2008 Guidelines for Device-based Therapy of Cardiac Rhythm Abnormalities: A Report of the
American College of Cardiology/American Heart Association Task Force on Practice Guidelines (Writing Committee to Revise the ACC/AHA/NASPE 2002 Guideline Update for Implantation of Cardiac Pacemakers and Antiarrhythmia Devices) Developed in Collaboration with the American Association for Thoracic Surgery and Society of Thoracic Surgeons," Journal of the American College of Cardiology, Vol. 51, No. 21, 2008, pp. 1-62. doi:10.1016/j.jacc.2008.02.032

[5] J. G. Cleland, J. C. Daubert, E. Erdmann, et al., “Cardiac Resynchronization-Heart failure (CARE-HF) Study Investigators: The Effect of Cardiac Resynchronization on Morbidity and Mortality of Heart Failure," The New England Journal of Medicine, Vol. 352, No. 15, 2005, pp. 1539-1549. doi:10.1056/NEJMoa050496

[6] C. Alonso, C. Leclercq, F. R. d'Allonnes, et al., "Six Year Experience of Transvenous Left Ventricular Lead Implantation for Permanent Left Biventricular Pacing in Patients with Advanced Heart Failure: Technical Aspects,” Heart, Vol. 86, No. 4, 2001, pp. 405-410. doi:10.1136/heart.86.4.405

[7] J. L. Jansens, M. Jottrand, N. Preumont, E. Stoupel and D. de Canniere, "Robotic-Enhanced Biventricular Resynchronization: An Alternative to Endovenous Cardiac Resynchronization Therapy in Chronic Heart Failure," The Annals of Thoracic Surgery, Vol. 76, No. 2, 2003, pp. 413-417. doi:10.1016/S0003-4975(03)00435-1

[8] S. Phillip, M. D. Cuculich and S. Joseph, "Cardiac Resynchronization Therapy: What? Who? When? How?” The American Journal of Medicine, Vol. 124, No. 11, 2011, pp. 813-815. doi:10.1016/j.amjmed.2010.09.028

[9] D. J. Bradley, E. A. Bradley, K. L. Baughman, et al., "Cardiac Resynchronization and Death from Progressive Heart Failure: A Meta-Analysis of Randomized Controlled Trials," Journal of the American Medical Association, Vol. 289, 2003, pp. 730-740. doi:10.1001/jama.289.6.730

[10] K. Perisinakis, N. Theocharopoulos, J. Damilakis, et al., "Fluoroscopically Guided Implantation of Modern Cardiac Resynchronization Devices Radiation Burden to the Patient and Associated Risks," Journal of the American College of Cardiology, Vol. 46, No. 12, 2005, pp. 23352339. doi:10.1016/j.jacc.2005.01.070

[11] C. Butter, T. Schau, J. Meyhoefer, et al., "Radiation Exposure of Patient and Physicians during Implantation and Upgrade of Cardiac Resynchronization Devices,” PACE, Vol. 33, 2010, pp. 1003-1012.

[12] H. Mair, J. Sachweh, B. Meuris, et al., "Surgical Epicardial Left Ventricular Lead Versus Coronary Sinus Lead Placement in Biventricular Pacing," European Journal of Cardio-Thoracic Surgery, Vol. 27, No. 2, 2005, pp. 235242. doi:10.1016/j.ejcts.2004.09.029 